Article

\title{
Implications of COVID-19 Restriction Measures in Urban Air Quality of Thessaloniki, Greece: A Machine Learning Approach
}

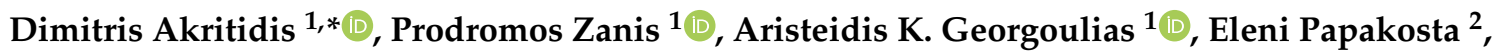 \\ Paraskevi Tzoumaka ${ }^{3}$ and Apostolos Kelessis ${ }^{3}$ \\ 1 Department of Meteorology and Climatology, School of Geology, Aristotle University of Thessaloniki, \\ 54124 Thessaloniki , Greece; zanis@geo.auth.gr (P.Z.); ageor@auth.gr (A.K.G.) \\ 2 Department of Environment and Hydroeconomy, Directorate of Environment, Industry, \\ Energy and Natural Resources, of the Region of Central Macedonia, 54642 Thessaloniki, Greece; \\ E.Papakosta@pkm.gov.gr \\ 3 Department of Environment of the Municipality of Thessaloniki, 54642 Thessaloniki, Greece; \\ tzoumaka@envdimosthes.gr (P.T.); kelesis@envdimosthes.gr (A.K.) \\ * Correspondence: dakritid@geo.auth.gr
}

check for updates

Citation: Akritidis, D.; Zanis, P.; Georgoulias, A.K.; Papakosta, E.; Tzoumaka, P.; Kelessis, A. Implications of COVID-19 Restriction Measures in Urban Air Quality of Thessaloniki, Greece: A Machine Learning Approach. Atmosphere 2021, 12, 1500. https://doi.org/10.3390/ atmos 12111500

Academic Editors: Gunnar W. Schade, Nicole Mölders, Daniele Contini, Gabriele Curci, Francesca Costabile, Prashant Kumar and Chris G. Tzanis

Received: 14 September 2021 Accepted: 10 November 2021 Published: 14 November 2021

Publisher's Note: MDPI stays neutral with regard to jurisdictional claims in published maps and institutional affiliations.

Copyright: (c) 2021 by the authors. Licensee MDPI, Basel, Switzerland. This article is an open access article distributed under the terms and conditions of the Creative Commons Attribution (CC BY) license (https:// creativecommons.org/licenses/by/ $4.0 /)$.

\begin{abstract}
Following the rapid spread of COVID-19, a lockdown was imposed in Thessaloniki, Greece, resulting in an abrupt reduction of human activities. To unravel the impact of restrictions on the urban air quality of Thessaloniki, $\mathrm{NO}_{2}$ and $\mathrm{O}_{3}$ observations are compared against the business-asusual (BAU) concentrations for the lockdown period. BAU conditions are modeled, applying the XGBoost (eXtreme Gradient Boosting) machine learning algorithm on air quality and meteorological surface measurements, and reanalysis data. A reduction in $\mathrm{NO}_{2}$ concentrations is found during the lockdown period due to the restriction policies at both AGSOFIA and EGNATIA stations of $-24.9[-26.6,-23.2] \%$ and $-18.4[-19.6,-17.1] \%$, respectively. A reverse effect is revealed for $\mathrm{O}_{3}$ concentrations at AGSOFIA with an increase of 12.7 [10.8, 14.8]\%, reflecting the reduced $\mathrm{O}_{3}$ titration by $\mathrm{NO}_{x}$. The implications of COVID-19 lockdowns in the urban air quality of Thessaloniki are in line with the results of several recent studies for other urban areas around the world, highlighting the necessity of more sophisticated emission control strategies for urban air quality management.
\end{abstract}

Keywords: COVID-19; air quality; machine learning; $\mathrm{NO}_{2} ; \mathrm{O}_{3}$; Thessaloniki; Greece

\section{Introduction}

Severe acute respiratory syndrome coronavirus 2 (SARS-CoV-2), the virus responsible for coronavirus disease 2019 (COVID-19) [1], was first reported in Wuhan, China [2] in late December 2019. Its high contagiousness [3] and the substantial early undocumented infections [4] facilitated the rapid worldwide spread of COVID-19, which was confirmed as a pandemic by the World Health Organization (WHO) in March 2020 [5]. In the absence of vaccinations, and to control the COVID-19 outbreak, several social, working, and transportation restrictions were gradually imposed around the world [6], with the strictness and duration of the so-called "lockdowns" varying by country.

The sharp reduction in human activities, as a result of restrictions measures, resulted in a decrease of major air pollutants, such as carbon dioxide $\left(\mathrm{CO}_{2}\right)[6,7]$ and nitrogen dioxide $\left(\mathrm{NO}_{2}\right)[8,9]$. Assessing the impact of COVID-19-associated anthropogenic emissions decline on air quality is a challenging task, as weather variability should also be considered [10], before attributing air pollutant concentration changes to COVID-19 restrictions alone. Recently, several studies have investigated the potential $\mathrm{NO}_{2}$ and $\mathrm{O}_{3}$ benefits ascribed to COVID-19 related emission reductions using statistical (machine learning, multivariate regression, difference-in-difference, generalized additive models) [11-14] and/or modeling [15-17] approaches. In particular, Keller et al. [18] and Grange et al. [11] explored the implications of COVID-19 restrictions in $\mathrm{NO}_{2}$ and $\mathrm{O}_{3}$ concentrations around 
the globe and in Europe, respectively, while other studies were performed for individual countries [17,19-23] and cities [24-26]. Overall, in urban environments, $\mathrm{NO}_{x}$ reductions during the COVID-19 lockdowns were followed by $\mathrm{O}_{3}$ increases [27,28]. Apart from reduced $\mathrm{O}_{3}$ titration by $\mathrm{NO}_{x}$, the increasing $\mathrm{O}_{3}$ pollution is also subject to variations of volatile organic compounds (VOC) emissions [29].

Thessaloniki, located at the northern part of Greece, is the second largest city of the country, with over one million inhabitants in its metropolitan area. In addition, the city is located within a local pollution hot spot [30]. In accordance with the national restrictions imposed during the COVID-19 outbreak, Thessaloniki's residents strictly limited their social, working, and educational activities. In particular, and after the first confirmed COVID-19 case in Thessaloniki (first in Greece also) on 26 February 2020, the following actions were taken:

- 11 March 2020: the operations of educational institutions, at all levels nationwide, were suspended.

- $\quad 14$ to 18 March 2020: coffee shops, restaurants, bars, markets, tourism services, and museums were closed, and several social activities were held.

- 23 March 2020: a strict lockdown was applied with significant restrictions on the movement of citizens throughout the territory.

The reverse process-in regard to the lifting of restrictions-was applied as follows:

- 5 May 2020: a gradual lifting of restrictions was introduced.

- 11 May 2020: reopening of markets.

- 25 May 2020: reopening of coffee shops, restaurants, and bars.

- 1 July 2020: reopening of tourism services.

As COVID-19 cases increased in late October 2020, and considering the available epidemiological data, the government announced a second strict lockdown in Thessaloniki, which was soon later imposed across the whole country.

The present study assesses the impacts of COVID-19 restriction policies on the urban air quality $\left(\mathrm{NO}_{2}\right.$ and $\left.\mathrm{O}_{3}\right)$ of Thessaloniki, Greece, using $\mathrm{NO}_{2}$ and $\mathrm{O}_{3}$ measurements from two ground-based stations, meteorological observations from one meteorological station, high-resolution meteorological reanalysis data, and the so-called XGBoost (eXtreme Gradient Boosting) machine learning algorithm. Section 2 presents the observational and reanalysis data used in the analysis, providing also a description of the applied XGBoost algorithm and the overall methodological approach. In Section 3, the main results are presented and discussed, in regard to recent research findings. Finally, Section 4 summarizes the key findings of the study.

\section{Materials and Methods}

\subsection{Data Description}

Air quality data from two ground-based stations located in the urban area of Thessaloniki are used in the analysis. $\mathrm{NO}_{2}$ and $\mathrm{O}_{3}$ hourly concentration measurements from the Agia Sofia Square station (hereafter called AGSOFIA) $\left(40.634^{\circ} \mathrm{N}, 22.945^{\circ} \mathrm{E}\right)$, from 2018 to 2020, were provided by the Department of Environment and Hydroeconomy of the Region of Central Macedonia. AGSOFIA is a low altitude $(27 \mathrm{~m})$ station located in Thessaloniki city center and is characterized as an urban-traffic station. The $\mathrm{NO}_{x}\left(\mathrm{NO}-\mathrm{NO}_{2}-\mathrm{NO}_{x}\right)$ analyzer is the HORIBA Ltd. (Kyoto, Japan) model APNA-360, based on the chemiluminescence measurement technique, with a detection limit of $0.5 \mathrm{ppb}$, while the calibration of the instrument is performed according to the technical standards. The $\mathrm{O}_{3}$ analyzer is the HORIBA Ltd. model APOA-360, using the principle of UV fluorescence, with a detection limit of $0.5 \mathrm{ppb}$ and a calibration according to the technical standards.

In addition, $\mathrm{NO}_{2}$ hourly concentrations from the Egnatia station (hereafter called EGNATIA) $\left(40.638^{\circ} \mathrm{N}, 22.941^{\circ} \mathrm{E}\right)$, from 2018 to 2020, were provided by the Environmental Department of the Municipality of Thessaloniki. EGNATIA station is an urban-traffic station in the city center of Thessaloniki with an elevation of $11 \mathrm{~m}$. The $\mathrm{NO}_{x}\left(\mathrm{NO}-\mathrm{NO}_{2}-\right.$ 
$\mathrm{NO}_{x}$ ) analyzer is the Envea (environment s.a.) model AC32M, which is in compliance with; EN 14211 (2012); U.S. EPA approved as compliant, no. RFNA-0202-146; certified by the TÜV report $\mathrm{N}^{\circ}$ 936/21205818/C; and ISO 7996, VDI4202. The measurement technique is based on chemiluminescence, with a detection limit of $0.4 \mathrm{ppb}$. The calibration of the instrument is performed on a monthly basis with the gas phase titration technique and calibration gas cylinders. Descriptive statistics for $\mathrm{NO}_{2}$ and $\mathrm{O}_{3}$ concentrations at AGSOFIA station, and $\mathrm{NO}_{2}$ concentrations at EGNATIA station, from 1 January 2018 to 31 December 2019, are provided in Table S1 of the Supplementary Materials.

Hourly meteorological data from the meteorological station of the Aristotle University of Thessaloniki (hereafter called METEO-AUTH) were also used, for the time period 2018 to 2020, including temperatures at $2 \mathrm{~m}$, mean sea level pressure, wind speed at $10 \mathrm{~m}$, total precipitation, relative humidity, and total radiation. METEO-AUTH is located in the Aristotle University Campus at an altitude of $32 \mathrm{~m}$, being in close proximity to the aforementioned air quality stations ( $\sim 1 \mathrm{~km}$ from AGSOFIA and $\sim 1.5 \mathrm{~km}$ from EGNATIA). The location of the air quality and meteorological stations is depicted in Figure 1.

Moreover, hourly data of boundary layer height, wind speed at $10 \mathrm{~m}$, temperature at $2 \mathrm{~m}$, mean sea level pressure, and total radiation for the period from 2018 to 2020, were obtained from the state-of-the-art ERA5 reanalysis dataset [31]. ERA5 is issued by the European Centre for Medium-Range Weather Forecasts (ECMWF) and produced with the 4D-Var data assimilation and model forecasts of the ECMWF CY41R2 Integrated Forecast System (IFS), including 137 hybrid sigma/pressure levels in the vertical and a horizontal resolution of $0.25^{\circ} \times 0.25^{\circ}$. The ERA5 data were extracted for the grid cell $\left(22.95^{\circ} \mathrm{E}\right.$, $40.65^{\circ} \mathrm{N}$ ) that includes the air quality and meteorological stations.

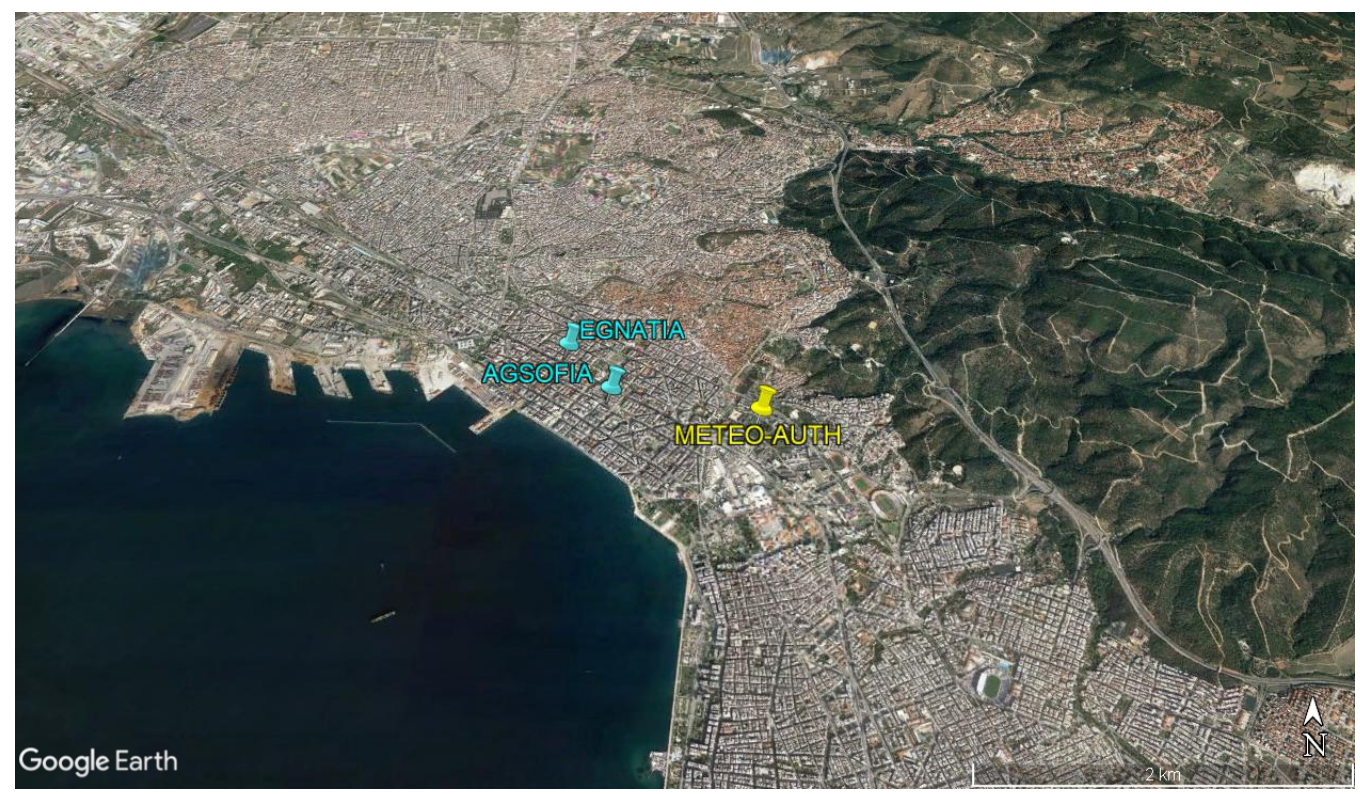

Figure 1. Location of air-quality (cyan) and meteorological (yellow) measurement stations in Thessaloniki, Greece. Map data @2019 Google.

\subsection{Machine Learning Approach}

\subsubsection{Business as Usual (BAU) Model}

Here, we apply the XGBoost machine learning algorithm [32] to model $\mathrm{NO}_{2}$ and $\mathrm{O}_{3}$ hourly concentrations at the air quality stations, in order to unravel the impact of COVID-19 restrictions on the observed air quality. XGBoost is a supervised learning technique based on the ensemble of gradient boosting decision trees, which is nowadays widely used in data science due to its scalability, speed, and performance [32]. Detailed information on the XGBoost algorithm, hyperparameters, and implementation can be found at https: / / xgboost.readthedocs.io/en/latest/index.html (accessed on 11 November 2021). Here, the python XGBoost library is used. 
For each air quality monitoring station and species, we built an XGBoost model using meteorological and time explanatory variables (so-called features) to explain the observed time-varying concentrations of the examined species. A past period was used for the training of the models, which represents a business-as-usual (BAU) situation. Subsequently, we applied the BAU model for the COVID-19 period in order to predict what would be the expected species hourly concentrations during this period in BAU conditions (absence of restriction policies). The residuals of the observations and BAU during the COVID-19 period reveal the impact of COVID-19 restrictions on the observed air quality. The benefit of the applied approach is that natural meteorological variability is consider before extracting the implications for air quality, unlike simply subtracting species concentrations during past periods from the respective concentrations during the COVID-19 period. Similar XGBoost-based machine learning approaches for the same scientific purpose were also applied recently by Keller et al. [18] and Granella et al. [33].

The air quality data (target variables) at both examined stations exhibit a data completeness $\geq 70 \%$ for the train period (1 January 2018 to 31 December 2019). The meteorological features include observations of air temperature at $2 \mathrm{~m}$, total precipitation, mean sea level pressure, relative humidity, wind speed at $10 \mathrm{~m}$, and total radiation, as well as ERA5 boundary layer height. Missing data of air temperature at $2 \mathrm{~m}(\sim 0.4 \%)$, mean sea level pressure $(\sim 0.4 \%)$, total radiation $(\sim 5.3 \%)$, and wind speed at $10 \mathrm{~m}(\sim 8 \%)$ are filled by the ERA5 reanalysis. The correlation coefficients between observations and ERA5 hourly values for temperature at $2 \mathrm{~m}$, mean sea level pressure, total radiation, and wind speed are $0.97,0.98,0.93$, and 0.65 , respectively. The wind direction was initially included in the BAU model, but as it had no significant contribution, it was excluded. The time explanatory variables include hour of the day, day of week, and month, and were created using the one-hot encoding method.

\subsubsection{Hyperparameter Tuning}

Prior to the creation of the XGBoost machine learning model for prediction, two basic processes are essential; the hyperparameters tuning and testing of the model performance on unseen data. The hyperparameters are a set of parameters that shape the learning process and, thus, control the overall behavior of the XGBoost model. To this end, we perform a tuning of the hyperparameters max_depth, n_estimators, min_child_weight, sub_sample, eta, reg_alpha, reg_lambda, and gamma using the Hyperopt Python library [34] that uses a form of Bayesian optimization, providing the hyperparameters that minimize/maximize a specified metric $\left(\mathrm{R}^{2}\right.$ here) for the given model. For as fair as possible tuning, and to avoid overfitting, we apply an 8-fold cross-validation with shuffle split to the dataset that extended from 1 January 2018 to 31 December 2019. The mean (out of eight cross validations) $\mathrm{R}^{2}$ values during the tuning process for $\mathrm{NO}_{2}$ at AGSOFIA, $\mathrm{O}_{3}$ at AGSOFIA, and $\mathrm{NO}_{2}$ at EGNATIA, are $0.67,0.82$, and 0.57 , respectively. With the selected hyperparameters (see Table S2 in the Supplementary Materials) applied, the XGBoost model (BAU) is trained over the period from 1 January 2018 to 31 December 2019, applying the "early stopping" technique that terminates training at the point where performance on the test dataset starts to decrease while performance on the training dataset continues to improve, in order to avoid overfitting.

\subsubsection{Evaluation of BAU Model}

To gain confidence in the BAU model use, we evaluate its prediction performance from 1 January to 15 February 2020 (1 January to 10 February 2020, for the EGNATIA station due to missing data), a period which was not included in the train process and, thus, is suitable for an independent evaluation. For brevity, we present evaluation results only for the AGSOFIA station, while for the EGNATIA station, the respective results are included as Supplementary Materials (Figure S1). Figure 2a presents the observed and BAU (predicted) time series of $\mathrm{NO}_{2}$ hourly concentrations at the AGSOFIA station, indicating a good agreement between observations and BAU during the test period, with a Pearson 
correlation coefficient (R) of 0.83 , a mean bias (MB) of $-0.19 \mu \mathrm{g} \mathrm{m}^{-3}$, and a normalized root mean squared error (NRMSE) of 0.28 . The former is also confirmed by the scatter plot of the observed and BAU $\mathrm{NO}_{2}$ hourly concentrations shown in Figure $2 \mathrm{~b}$. Noteworthy are the normally distributed $\mathrm{NO}_{2}$ concentration residuals (Figure 2c), revealing that the BAU model over- and underpredicts with a relatively equal probability, underestimating/overestimating high/low observed $\mathrm{NO}_{2}$ concentrations. As for $\mathrm{O}_{3}$, Figure 3a shows a good comparison between the observed and $\mathrm{BAU}$ time series of $\mathrm{O}_{3}$ hourly concentrations at AGSOFIA, with an $\mathrm{R}$ of 0.83 , a MB of $-3.17 \mu \mathrm{g} \mathrm{m}^{-3}$, and an NRMSE of 0.45 . Similar to $\mathrm{NO}_{2}$, the $\mathrm{O}_{3}$ concentration residuals follow a bell-shaped pattern allowing for valid inferences. Regarding $\mathrm{NO}_{2}$ at EGNATIA station, the observed and BAU time series exhibit an $\mathrm{R}$ of 0.7 , a MB of $2.99 \mu \mathrm{g} \mathrm{m}^{-3}$, and an RMSE of 0.23 , with normally distributed residuals (Figure $\mathrm{S} 1$ of the Supplementary Materials). For the train period the $\mathrm{BAU}$ model for $\mathrm{NO}_{2}$ at AGSOFIA, $\mathrm{O}_{3}$ at AGSOFIA, and $\mathrm{NO}_{2}$ at EGNATIA, exhibit skill scores of $\mathrm{R}=0.96 / \mathrm{MB}$ $=0 \mu \mathrm{g} \mathrm{m}^{-3} / \mathrm{RMSE}=0.14, \mathrm{R}=0.98 / \mathrm{MB}=0 \mu \mathrm{g} \mathrm{m}^{-3} / \mathrm{RMSE}=0.13$, and $\mathrm{R}=0.93 / \mathrm{MB}=$ $0 \mu \mathrm{g} \mathrm{m}^{-3} / \mathrm{RMSE}=0.12$, respectively, as also depicted in Figure S2 of the Supplementary Materials. The evaluation results for both train and test periods are in line with the respective results of the recent COVID-19-related studies by Grange et al. [11], Keller et al. [18], Petetin et al. [21].

\subsubsection{Estimation of Uncertainty}

For a more robust interpretation of the results, estimation of the uncertainty in the BAU model predictions is essential. To this end, two methodologies are applied to estimate the uncertainty of BAU predictions following Petetin et al. [21] and Keller et al. [18]. At first, the 2018-2019 period was randomly split in eight sub-periods, and subsequently, the BAU model was applied using seven sub-periods for train and the remaining for test, in an iterative process of eight steps. The hourly residuals (BAU-OBS) were then calculated and the following two methodologies were applied to estimate the uncertainty.

- Method1: following Petetin et al. [21], the 5th and 95th percentiles of the hourly residuals are found forming a fixed asymmetric $90 \%$ confidence interval for the hourly predictions. As our results are presented as a 1-month moving average, the 1-month moving average of the hourly residuals are calculated, and the respective 5th and 95th percentiles are used for the $90 \%$ confidence interval.

- Method 2: following Keller et al. [18], the standard deviation of the hourly residuals is used as the uncertainty of the hourly predictions. The temporal (monthly) average of the uncertainty is then calculated as follows:

$$
\bar{\sigma}^{2}=\sum_{i=1}^{N}\left(\frac{\sigma_{i}}{N}\right)^{2}
$$

where $\bar{\sigma}$ the mean uncertainty, $\sigma_{i}$ the hourly uncertainty, and $\mathrm{N}$ the sample size. Here we use the $2 \bar{\sigma}$ interval corresponding to an approximately $95 \%$ confidence interval.

The resulting uncertainties of each BAU model predictions are presented in Table 1.

Table 1. Uncertainty estimations $\left(\mu \mathrm{g} \mathrm{m}^{-3}\right)$ for BAU models predictions.

\begin{tabular}{cccc}
\hline & AGSOFIA NO & AGSOFIA O $_{\mathbf{3}}$ & EGNATIA NO $_{\mathbf{2}}$ \\
\hline 5th percentile of hourly residuals & -11.84 & -20.73 & -23.79 \\
95th percentile of hourly residuals & 10.25 & 20.99 & 22.47 \\
standard deviation of hourly residuals & 6.81 & 12.56 & 14.09 \\
monthly uncertainty interval (method 1) & {$[-0.44,+0.55]$} & {$[-0.69,+0.74]$} & {$[-0.92,+1.44]$} \\
monthly uncertainty interval (method 2) & {$[-0.51,+0.51]$} & {$[-0.94,+0.94]$} & {$[-1.05,+1.05]$} \\
\hline
\end{tabular}



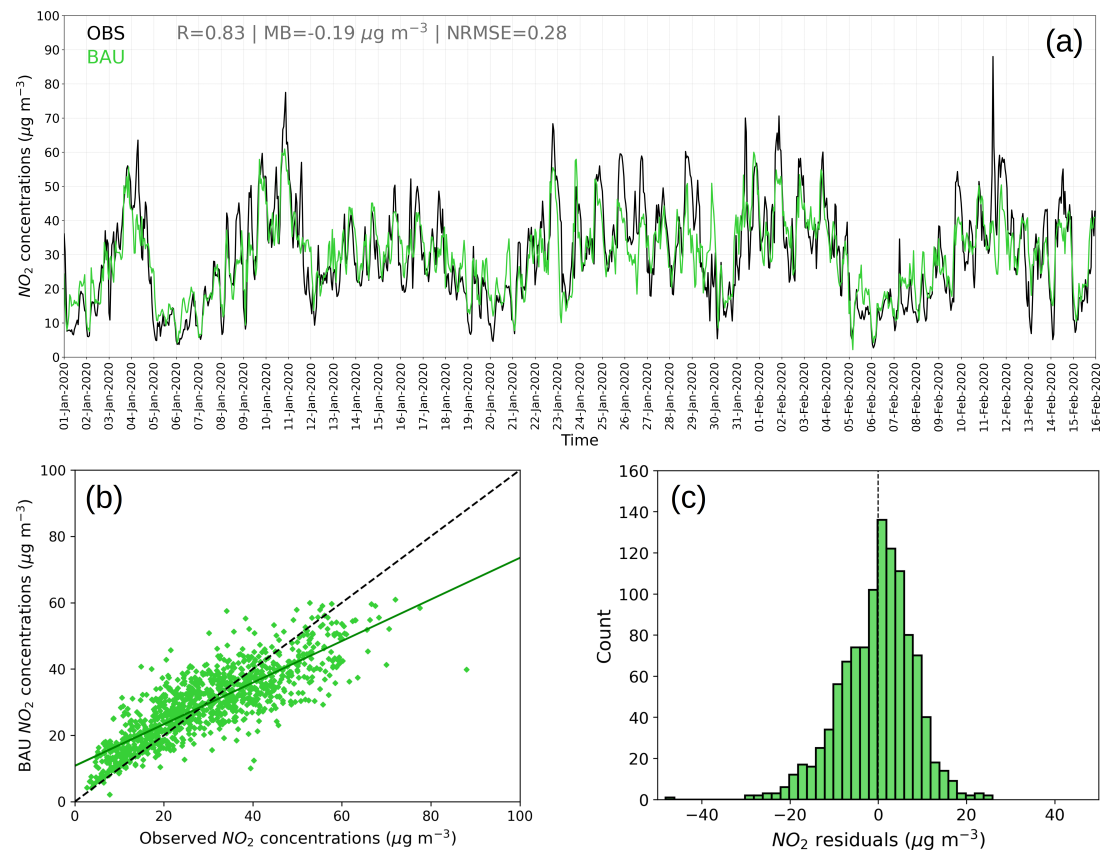

Figure 2. (a) Observed (black) and BAU (green) time series of $\mathrm{NO}_{2}$ hourly concentrations at AGSOFIA station from 1 January to 15 February 2020. (b) Scatter plot of observed and BAU $\mathrm{NO}_{2}$ hourly concentrations at AGSOFIA station from 1 January to 15 February 2020. The solid green line represents the regression line of the observed and $\mathrm{BAU} \mathrm{NO} 2$ concentrations, while the dashed black line is the 1:1 line. (c) Histogram of $\mathrm{NO}_{2}$ residual concentrations (BAU-observation) at AGSOFIA station during the time period from 1 January to 15 February 2020.
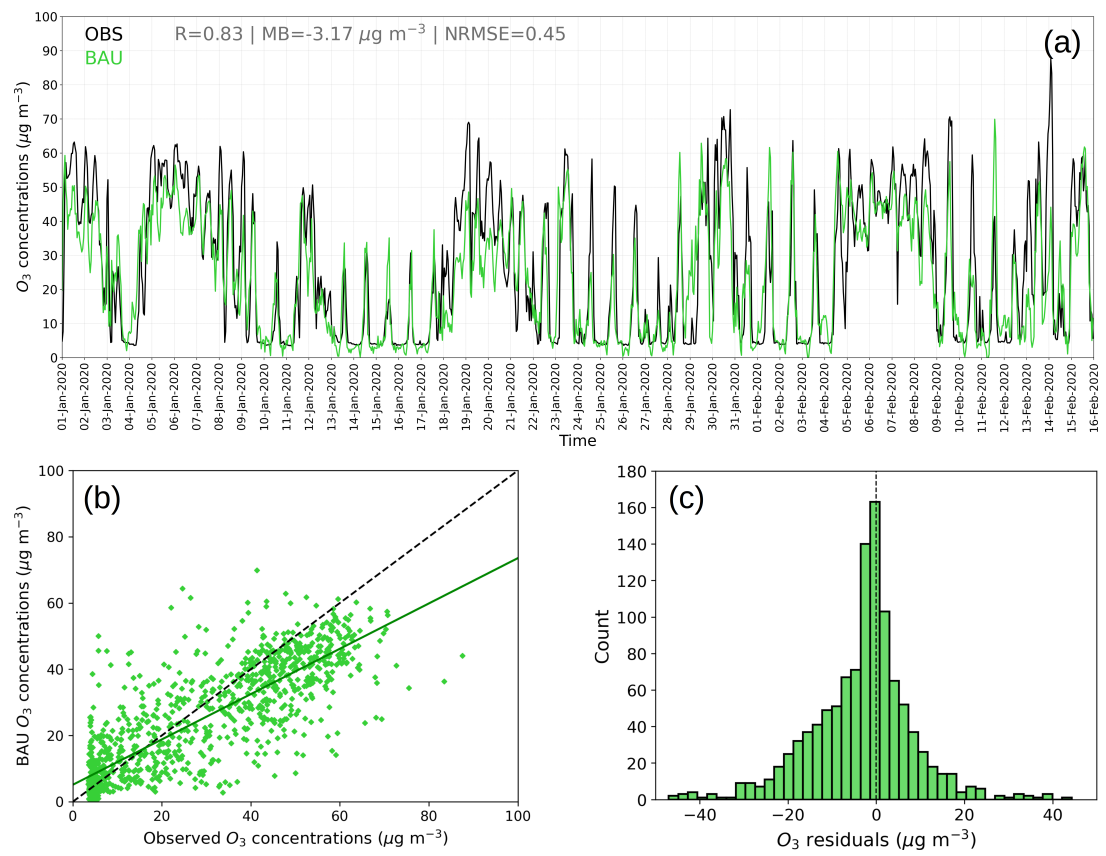

Figure 3. (a) Observed (black) and BAU (green) time series of $\mathrm{O}_{3}$ hourly concentrations at AGSOFIA station from 1 January to 15 February 2020. (b) Scatter plot of the observed and BAU $\mathrm{O}_{3}$ hourly concentrations at AGSOFIA station from 1 January to 15 February 2020. The solid green line represents the regression line of the observed and $\mathrm{BAU} \mathrm{O}_{3}$ concentrations, while the dashed black line is the 1:1 line. (c) Histogram of $\mathrm{O}_{3}$ residual concentrations (BAU-observation) at AGSOFIA station from 1 January to 15 February 2020. 


\section{Results}

To unravel the impact of COVID-19 restrictions on urban air quality of Thessaloniki, we compare the BAU-predicted $\mathrm{NO}_{2}$ and $\mathrm{O}_{3}$ concentrations during the COVID-19 period with the actual observations. To obtain more robust conclusions from the results, the $\mathrm{MB}$ of BAU 1-month moving average concentrations during the test period is removed (positive/negative bias is subtracted/added) from the respective BAU values during the lockdown period. This correction process is only applied for the reported in the text differences and percentage differences between observations and BAU, while in all figures, we present the original concentrations (without correction). As both uncertainty estimation methods presented in Section 2.2.4 give quite similar intervals, hereafter, only uncertainties obtained by method 2 are reported as $95 \%$ confidence interval enclosed in brackets.

Figure 4a presents the observed and $\mathrm{BAU}$ time series of $\mathrm{NO}_{2}$ 1-month moving average concentrations for the AGSOFIA station during the year 2020. Until the first lockdown at 16 March 2020, the observed $\mathrm{NO}_{2}$ time series followed closely the BAU $\mathrm{NO}_{2}$ time series, indicating that the observed situation before the lockdown was a BAU one. From 16 March to early May 2020, a distinct decrease of observed $\mathrm{NO}_{2}$ concentrations was seen in contrast to the respective BAU time series, which remained relatively constant. From early May 2020, and as the COVID-19 restrictions were gradually lifted, the observed $\mathrm{NO}_{2}$ concentrations were at first stabilized, and from early June 2020, increased, approaching the $\mathrm{NO}_{2} \mathrm{BAU}$ concentration levels. The residual (observation-BAU) of $\mathrm{NO}_{2}$ and $\mathrm{O}_{3}$ 1-month moving average concentrations are presented in Figure $4 \mathrm{c}$, indicating a sharp decrease of the $\mathrm{NO}_{2}$ residual concentrations, which, during the lockdown period (16 March to 5 May 2020) ranged from -0.6 to $-8.5 \mu \mathrm{g} \mathrm{m}^{-3}$ with an average value of $-5.7[-6.21,-5.19] \mu \mathrm{g} \mathrm{m}^{-3}$, reflecting the direct effect of COVID-19 restrictions in $\mathrm{NO}_{2}$ levels at AGSOFIA. The respective 1-month moving average $\mathrm{NO}_{2}$ percentage differences between observations and $\mathrm{BAU}$ depicted in Figure $4 \mathrm{~d}$ reveal a similar decrease for the same period ranging from -2.6 to $-39.1 \%$ with an average value of $-24.9[-26.6,-23.2] \%$. Recently, Keller et al. [18] examined observational data from 46 countries reporting that during the lockdowns, $\mathrm{NO}_{2}$ concentrations were on average $18 \%$ lower than BAU. At a European scale, Grange et al. [11] estimated a mean percentage change of $-34 \%$ for $\mathrm{NO}_{2}$ based on European traffic stations, using Bayesian inference to detect change points and subsequently the lockdown periods. As for Greece, Grivas et al. [24] using in situ observations found an $\mathrm{NO}_{2}$ decline of $32 \%$ compared to the pre-lockdown period in Athens, Greece, while Koukouli et al. [35] using satellite observations and a chemical transport model, attributed a $12 \%$ decrease of tropospheric $\mathrm{NO}_{2}$ columns at Thessaloniki during March to emissions changes.

As regards $\mathrm{O}_{3}$, prior to the lockdown, the observed and $\mathrm{BAU}$ concentrations varied similarly, while from the lockdown onset, the observed $\mathrm{O}_{3}$ levels started to diverge incrementally from the respective BAU levels up to early May 2020, returning close to BAU levels in mid-June 2020 (Figure $4 \mathrm{~b}$ ). The aforementioned $\mathrm{NO}_{2}$ decline was accompanied with a synchronous increase of $\mathrm{O}_{3}$ residual (observation-BAU) concentrations of an average value of $7[6.06,7.94] \mu \mathrm{g} \mathrm{m}^{-3}$ (range from 3 to $12.9 \mu \mathrm{g} \mathrm{m}^{-3}$ ) (Figure 4c) and percentage differences of an average value of $12.7[10.8,14.8] \%$ (range from 7 to $21 \%$ ) (Figure $4 \mathrm{~d}$ ). The clear anticorrelation ( $\mathrm{R}$ of -0.74 ) between $\mathrm{NO}_{2}$ and $\mathrm{O}_{3}$ residuals during the lockdown period (grey shaded areas in Figure 4c,d) reflects the link between $\mathrm{NO}_{x}$ and $\mathrm{O}_{3}$ chemistry, with reduced $\mathrm{NO}_{x}$ resulting in reduced $\mathrm{O}_{3}$ titration by $\mathrm{NO}$ and thus in enhanced $\mathrm{O}_{3}$ levels. Moreover, in a likely VOC-limited environment, a decline in $\mathrm{NO}_{x}$ leads in enhanced $\mathrm{O}_{3}$ production. The mean European percentage changes of $\mathrm{O}_{3}$ for traffic sites during the lockdowns was reported $30 \%$ by Grange et al. [11], mainly attributed to decreased $\mathrm{O}_{3}$ destruction via the titration cycle. Similar increases in European $\mathrm{O}_{3}$ concentrations during the lockdowns were also reported by Gualtieri et al. [20], Higham et al. [22], Tobías et al. [26], Sicard et al. [27], Putaud et al. [36]. 

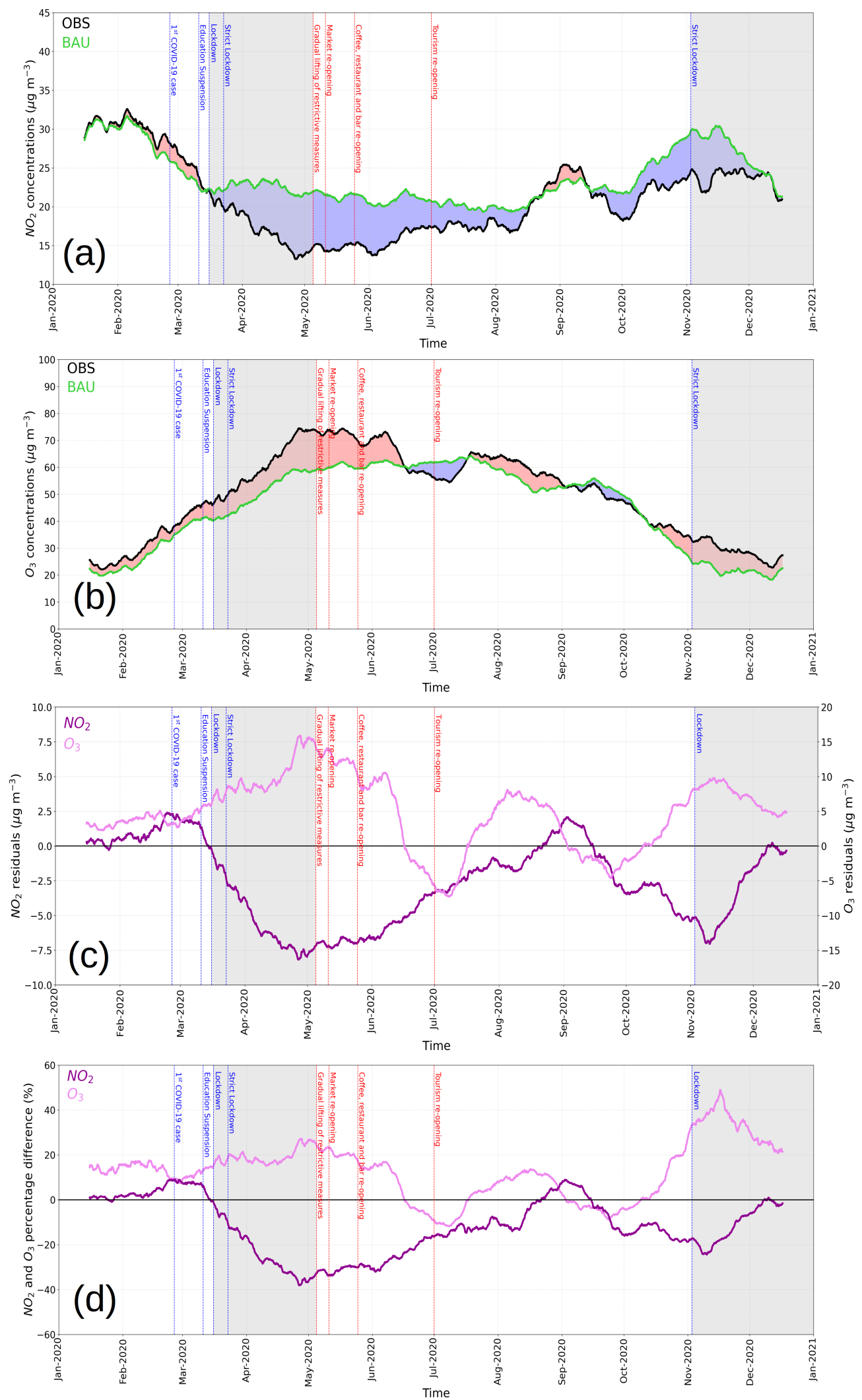

Figure 4. Observed (black) and $\mathrm{BAU}$ (green) time series of $\mathrm{NO}_{2}$ (a) and $\mathrm{O}_{3}$ (b) 1-month moving average concentrations at AGSOFIA station during the year 2020. Residual (observation-BAU) (c) and percentage differences (d) of $\mathrm{NO}_{2}$ (purple) and $\mathrm{O}_{3}$ (pink) 1-month moving average concentrations at AGSOFIA station during the year 2020. The gray shaded areas represent the lockdown periods. The blue/red shaded areas represent the decrease/increase of observed $\mathrm{NO}_{2}$ and $\mathrm{O}_{3}$ concentrations relative to the BAU conditions. 
The same behavior is revealed from the observed and BAU diurnal cycles of $\mathrm{NO}_{2}$ and $\mathrm{O}_{3}$ concentrations at AGSOFIA during the period from 16 March to 31 May 2020, shown in Figure 5. Both BAU and observed $\mathrm{NO}_{2}$ diurnal cycles exhibit two distinct peaks; an early morning due to rush-hour vehicle traffic and a late evening resulting from both emissions and accumulation, due to absence of sunlight inhibiting $\mathrm{NO}_{2}$ photolysis. The respective $\mathrm{O}_{3}$ diurnal cycles are characterized by a broad afternoon maximum owing to its photochemical production. Lower/higher $\mathrm{NO}_{2} / \mathrm{O}_{3}$ concentrations are observed throughout the day and night compared to BAU as depicted in Figure 5a,b. In particular, the diurnal cycles of $\mathrm{NO}_{2}$ and $\mathrm{O}_{3}$ residuals shown in Figure $5 \mathrm{c}$ indicate a reverse response $(\mathrm{R}=-0.88)$ of the two pollutants to the COVID-19 restrictions policies within the day. These are in line with the diurnal variations of $\mathrm{NO}_{2}$ and $\mathrm{O}_{3}$ anomalies during the lockdowns at several European megacities, such as Berlin, London, Brussels, Paris, Milan, and Madrid [37].
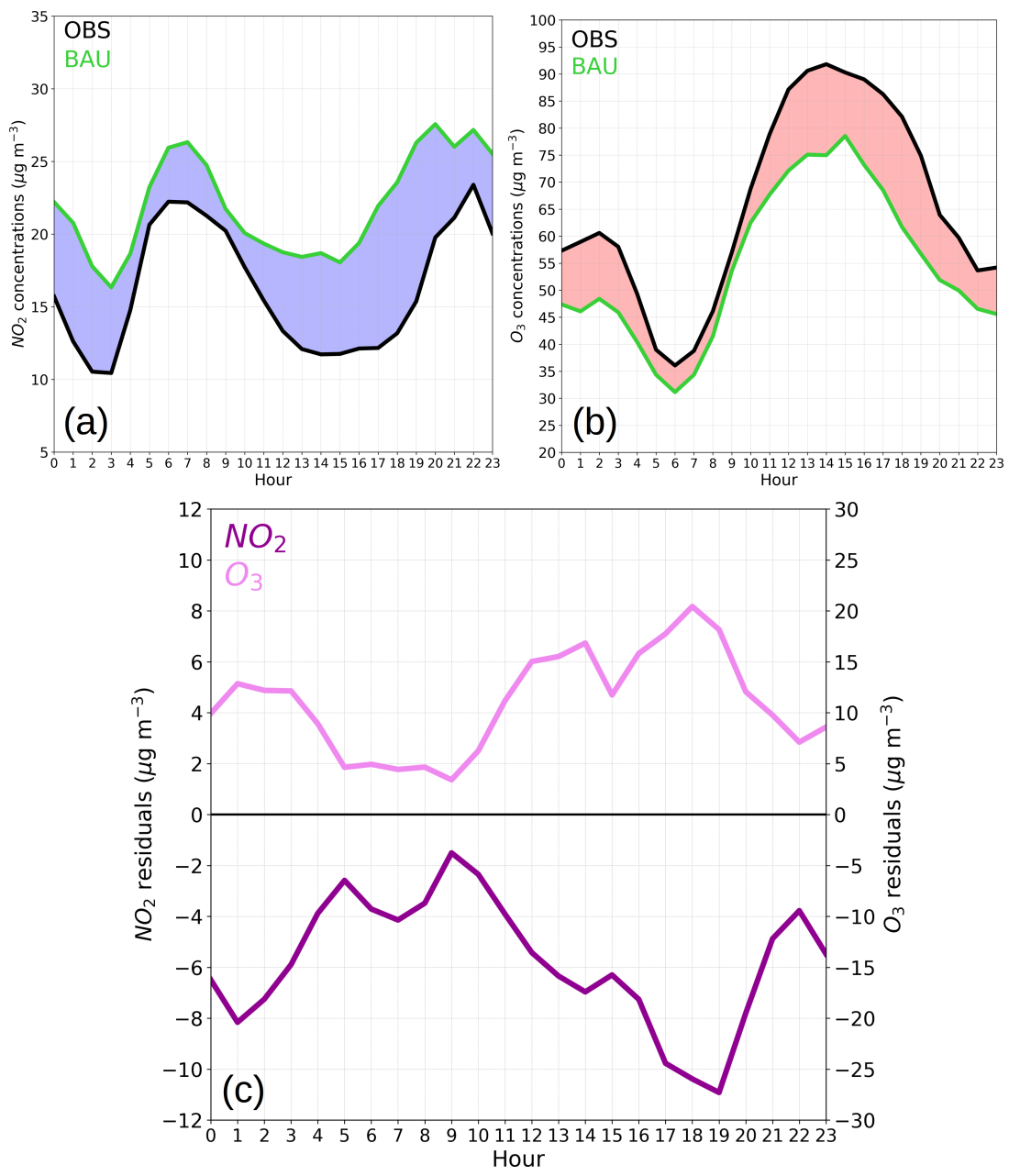

Figure 5. Observed (black) and BAU (green) diurnal cycles of $\mathrm{NO}_{2}(\mathbf{a})$ and $\mathrm{O}_{3}(\mathbf{b})$ concentrations at AGSOFIA station. The blue/red shaded areas represent the decrease/increase of observed $\mathrm{NO}_{2}$ and $\mathrm{O}_{3}$ concentrations relative to the BAU conditions. (c) Diurnal cycle of $\mathrm{NO}_{2}$ (purple) and $\mathrm{O}_{3}$ (pink) residual (observation-BAU) concentrations at AGSOFIA station. The examined period is from 16 March to 31 May 2020. Hours are in UTC.

Regarding the second lockdown imposed in early November 2020, although a decrease/increase of $\mathrm{NO}_{2} / \mathrm{O}_{3}$ levels is seen at AGSOFIA station as shown in Figure 4, these are not as pronounced as in the first lockdown, reflecting the greater intensity of the first lockdown. During the intermediate period between the two lockdowns, the observed $\mathrm{NO}_{2}$ and $\mathrm{O}_{3}$ concentrations are more close to $\mathrm{BAU}$ values compared to that during the lockdown periods. 
As for the second examined station, Figure 6 presents both the time series and diurnal cycles of observed and $\mathrm{BAU} \mathrm{NO} \mathrm{N}_{2}$ concentrations at the EGNATIA station. In agreement with the AGSOFIA station, a decrease of observed $\mathrm{NO}_{2}$ 1-month moving average concentrations was seen from early March 2020 relative to BAU concentrations with an average value of $-13.1[-14.2,-12] \mathrm{\mu g} \mathrm{m}^{-3}$ (Figure 6a), while the percentage difference between observations and BAU during the lockdown (16 March 2020 to 5 May 2020) ranged from $-7.3 \%$ to $-24.1 \%$ with an average value of $-18.4[-19.6,-17.1] \%$ (Figure $6 \mathrm{~b}$ ). From early May 2020 , and as the restrictions started to relax, the observed $\mathrm{NO}_{2}$ levels gradually increased, reaching near BAU values from mid-June 2020 onward. Regarding the second lockdown in early November 2020, this was not clearly reflected in the observed and residual $\mathrm{NO}_{2}$ concentrations. The diurnal cycle of the observed and $\mathrm{BAU} \mathrm{NO}_{2}$ concentrations at the EGNATIA station from 16 March to 31 May 2020, shown in Figure 6c, exhibits the same two-peak shape as that of the AGSOFIA station, revealing a clear decline of $\mathrm{NO}_{2}$ levels throughout the day and night during the first lockdown period.
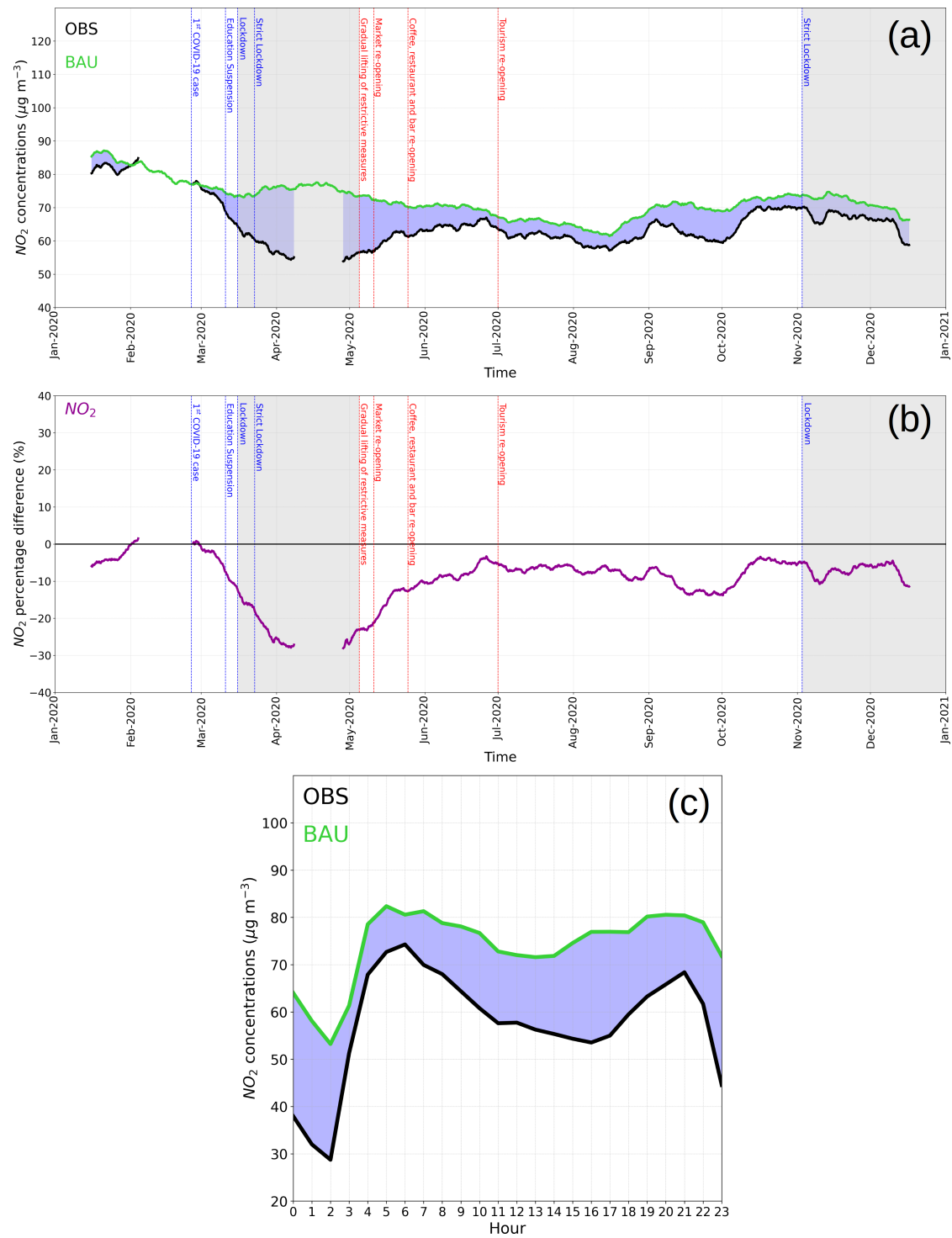

Figure 6. (a) Observed (black) and $\mathrm{BAU}$ (green) time series of $\mathrm{NO}_{2}$ 1-month moving average concentrations at the EGNATIA station during 2020. (b) Percentage differences of $\mathrm{NO}_{2}$ 1-month moving average concentrations between observations and BAU at EGNATIA station during 2020. (c) Observed (black) and BAU (green) diurnal cycle of $\mathrm{NO}_{2}$ concentrations at EGNATIA station from 16 March to 31 May 2020. Hours are in UTC. The blue/red shaded areas represent the decrease/increase of observed $\mathrm{NO}_{2}$ concentrations relative to the BAU conditions. 


\section{Conclusions}

This study investigated the impact of COVID-19 restriction policies on the urban air quality of Thessaloniki, Greece, using air quality and meteorological observations, ERA5 reanalysis data, and the XGBoost machine learning algorithm. Modeling $\mathrm{NO}_{2}$ and $\mathrm{O}_{3} \mathrm{BAU}$ concentrations and comparing with observations for the lockdown period, allowed the assessment of COVID-19 restriction footprints on the urban air quality of Thessaloniki. With the applied approach, the impact of weather variability was also considered.

Both AGSOFIA and EGNATIA urban-traffic stations exhibited an $\mathrm{NO}_{2}$ drop during the lockdown period (from 16 March to 5 May 2020) led by the COVID-19 restrictions, of $-24.9[-26.6,-23.2] \%$ and $-18.4[-19.6,-17.1] \%$, respectively, accompanied by an $12.7[10.8,14.8] \%$ increase of $\mathrm{O}_{3}$ at AGSOFIA. Similar conclusions arose from the diurnal variation of the pollutants during the lockdown, indicating lower/higher $\mathrm{NO}_{2} / \mathrm{O}_{3}$ levels relative to $\mathrm{BAU}$ throughout the day and night at both stations/AGSOFIA. The mirroring pattern of $\mathrm{NO}_{2}$ and $\mathrm{O}_{3}$ residuals during the lockdown in both time series and diurnal cycles back the view that a decline in $\mathrm{NO}_{x}$ results in $\mathrm{O}_{3}$ increase through a decrease of $\mathrm{O}_{3}$ titration, and presumably the enhanced $\mathrm{O}_{3}$ production in a likely VOC-limited regime. It should be noted that the aforementioned $\mathrm{O}_{3}$ increase at AGSOFIA, due to the COVID-19 restrictions, should not be generalized for other locations in Thessaloniki, where $\mathrm{O}_{3}$ might be governed by different photochemical regimes.

Consistent with recent studies on other urban areas worldwide, the $\mathrm{NO}_{2}$ decrease at Thessaloniki during the COVID-19 lockdown was associated with an $\mathrm{O}_{3}$ increase. Such reallife modeling scenarios, like the COVID-19 pandemic, provide tangible evidence that, for a better future air quality management in urban environments, a more sophisticated emissions control is required. To mitigate $\mathrm{O}_{3}$ pollution, $\mathrm{NO}_{x}$ reductions should be accompanied by VOC-targeted control strategies specifically designed for each urban environment.

Supplementary Materials: The following are available online at https: / www.mdpi.com/article / 10.3390 /atmos12111500/s1. Table S1: Descriptive statistics (mean, 10th percentile, 25th percentile, median, 75th percentile, 90th percentile, and standard deviation) for $\mathrm{NO}_{2}\left(\mu \mathrm{g} \mathrm{m}^{-3}\right)$ and $\mathrm{O}_{3}\left(\mu \mathrm{g} \mathrm{m}^{-3}\right)$ at AGSOFIA station, and $\mathrm{NO}_{2}\left(\mu \mathrm{g} \mathrm{m}^{-3}\right)$ at EGNATIA station, for the time period from 1 January 2018 to 31 December 2019. Table S2: XGBoost hyperparameters used for the BAU models. Figure S1: (a) Observed (black) and BAU (green) timeseries of $\mathrm{NO}_{2}$ hourly concentrations at EGNATIA station during the time period from 1 January to 10 February 2020. (b) Scatter plot of observed and $\mathrm{BAU} \mathrm{NO} \mathrm{NO}_{2}$ hourly concentrations at EGNATIA station during the time period from 1 January to 10 February 2020. The solid green line represents the regression line of the observed and BAU $\mathrm{NO}_{2}$ concentrations, while the dashed black line is the 1:1 line. (c) Histogram of $\mathrm{NO}_{2}$ residual concentrations (BAU-observation) at EGNATIA station during the time period from 1 January to 10 February 2020. Figure S2: Observed (black) and BAU (green) 1-month moving average concentrations during the train (left of the blue dashed line) and test (right of the blue dashed line) periods, along with the correlation coefficient (R), mean bias (MB), and normalized root mean square error (NRMSE) for the train period for AGSOFIA $\mathrm{NO}_{2}(\mathrm{a})$, AGSOFIA O 3 (b), and EGNATIA $\mathrm{NO}_{2}$ (c).

Author Contributions: Conceptualization, D.A.; methodology, D.A., P.Z., A.K.G.; software, D.A.; validation, D.A., E.P., P.T., A.K.; formal analysis, D.A.; investigation, D.A., P.Z., A.K.G.; resources, D.A., E.P., P.T., A.K.; data curation, D.A., E.P., P.T., A.K.; writing-original draft preparation, D.A.; writing-review and editing, D.A., P.Z., A.K.G.; visualization, D.A.; supervision, D.A.; project administration, D.A. All authors have read and agreed to the published version of the manuscript.

Funding: This research received no external funding.

Institutional Review Board Statement: Not applicable.

Informed Consent Statement: Not applicable. 
Data Availability Statement: The air quality and meteorological observations used in the present study are available from the authors upon request. The ECMWF ERA5 reanalysis data [38] were obtained from the Copernicus Climate Change Service Climate Data Store (CDS) (https://cds. climate.copernicus.eu/cdsapp\#!/ dataset/reanalysis-era5-single-levels?tab=form) (accessed on 11 November 2021).

Acknowledgments: We acknowledge ECMWF for distributing the ERA5 reanalysis data, generated using Copernicus Climate Change Service Information 2021. This study contains modified Copernicus Climate Change Service Information 2021. Neither the European Commission nor ECMWF are responsible for any use that may be made of the Copernicus Information or data it contains.

Conflicts of Interest: The authors declare no conflict of interest.

\section{References}

1. WHO. Naming the Coronavirus Disease (COVID-19) and the Virus that Causes It. 2020. Available online: https: //www.who.int/emergencies/diseases/novel-coronavirus-2019/technical-guidance/naming-the-coronavirus-disease(covid-2019)-and-the-virus-that-causes-it (accessed on 11 November 2021).

2. WHO. Pneumonia of Unknown Cause-China. 2020. Available online: https://www.who.int/csr/don/05-january-2020pneumonia-of-unkown-cause-china/en/ (accessed on 11 November 2021).

3. Sanche, S.; Lin, Y.T.; Xu, C.; Romero-Severson, E.; Hengartner, N.; Ke, R. High contagiousness and rapid spread of severe acute respiratory syndrome coronavirus 2. Emerg. Infect. Dis. 2020, 26, 1470-1477. [CrossRef]

4. Li, R.; Pei, S.; Chen, B.; Song, Y.; Zhang, T.; Yang, W.; Shaman, J. Substantial undocumented infection facilitates the rapid dissemination of novel coronavirus (SARS-CoV-2). Science 2020, 368, 489-493. doi: 10.1126/science.abb3221. [CrossRef]

5. WHO. WHO Director-General's Opening Remarks at the Media Briefing on COVID-19, 11 March 2020. Available online: https:/ / www.who.int/director-general/speeches/detail/who-director-general-s-opening-remarks-at-the-media-briefingon-covid-19---11-march-2020 (accessed on 11 November 2021).

6. Le Quéré, C.; Jackson, R.B.; Jones, M.W.; Smith, A.J.; Abernethy, S.; Andrew, R.M.; De-Gol, A.J.; Willis, D.R.; Shan, Y.; Canadell, J.G.; et al. Temporary reduction in daily global $\mathrm{CO}_{2}$ emissions during the COVID-19 forced confinement. Nat. Clim. Chang. 2020, 10, 647-653. [CrossRef]

7. Liu, Z.; Ciais, P.; Deng, Z.; Lei, R.; Davis, S.J.; Feng, S.; Zheng, B.; Cui, D.; Dou, X.; Zhu, B.; et al. Near-real-time monitoring of global $\mathrm{CO}_{2}$ emissions reveals the effects of the COVID-19 pandemic. Nat. Commun. 2020, 11, 5172. [CrossRef] [PubMed]

8. Bauwens, M.; Compernolle, S.; Stavrakou, T.; Müller, J.F.; van Gent, J.; Eskes, H.; Levelt, P.F.; van der A.R.; Veefkind, J.P.; Vlietinck, J.; et al. Impact of Coronavirus Outbreak on $\mathrm{NO}_{2}$ Pollution Assessed Using TROPOMI and OMI Observations. Geophys. Res. Lett. 2020, 47, e2020GL087978. doi: 10.1029/2020GL087978. [CrossRef] [PubMed]

9. Liu, F.; Page, A.; Strode, S.A.; Yoshida, Y.; Choi, S.; Zheng, B.; Lamsal, L.N.; Li, C.; Krotkov, N.A.; Eskes, H.; et al. Abrupt decline in tropospheric nitrogen dioxide over China after the outbreak of COVID-19. Sci. Adv. 2020, 6, eabc2992. doi: 10.1126/sciadv.abc2992. [CrossRef] [PubMed]

10. Grange, S.K.; Carslaw, D.C. Using meteorological normalisation to detect interventions in air quality time series. Sci. Total Environ. 2019, 653, 578-588. doi: 10.1016/j.scitotenv.2018.10.344. [CrossRef]

11. Grange, S.K.; Lee, J.D.; Drysdale, W.S.; Lewis, A.C.; Hueglin, C.; Emmenegger, L.; Carslaw, D.C. COVID-19 lockdowns highlight a risk of increasing ozone pollution in European urban areas. Atmos. Chem. Phys. 2021, 21, 4169-4185. doi: 10.5194/acp-21-41692021. [CrossRef]

12. Cameletti, M. The Effect of Corona Virus Lockdown on Air Pollution: Evidence from the City of Brescia in Lombardia Region (Italy). Atmos. Environ. 2020, 239, 117794. doi: 10.1016/j.atmosenv.2020.117794. [CrossRef]

13. Liu, F.; Wang, M.; Zheng, M. Effects of COVID-19 lockdown on global air quality and health. Sci. Total Environ. 2021, 755, 142533. doi: 10.1016/j.scitotenv.2020.142533. [CrossRef]

14. Ordóñez, C.; Garrido-Perez, J.M.; García-Herrera, R. Early spring near-surface ozone in Europe during the COVID-19 shutdown: Meteorological effects outweigh emission changes. Sci. Total Environ. 2020, 747, 141322. doi: 10.1016/j.scitotenv.2020.141322. [CrossRef] [PubMed]

15. Evangeliou, N.; Platt, S.M.; Eckhardt, S.; Lund Myhre, C.; Laj, P.; Alados-Arboledas, L.; Backman, J.; Brem, B.T.; Fiebig, M.; Flentje, H.; et al. Changes in black carbon emissions over Europe due to COVID-19 lockdowns. Atmos. Chem. Phys. 2021, 21, 2675-2692. doi: 10.5194/acp-21-2675-2021. [CrossRef]

16. Guevara, M.; Jorba, O.; Soret, A.; Petetin, H.; Bowdalo, D.; Serradell, K.; Tena, C.; Denier van der Gon, H.; Kuenen, J.; Peuch, V.H.; et al. Time-resolved emission reductions for atmospheric chemistry modelling in Europe during the COVID-19 lockdowns. Atmos. Chem. Phys. 2021, 21, 773-797. doi: 10.5194/acp-21-773-2021. [CrossRef]

17. Xing, J.; Li, S.; Jiang, Y.; Wang, S.; Ding, D.; Dong, Z.; Zhu, Y.; Hao, J. Quantifying the emission changes and associated air quality impacts during the COVID-19 pandemic on the North China Plain: a response modeling study. Atmos. Chem. Phys. 2020, 20, 14347-14359. doi: 10.5194/acp-20-14347-2020. [CrossRef] 
18. Keller, C.A.; Evans, M.J.; Knowland, K.E.; Hasenkopf, C.A.; Modekurty, S.; Lucchesi, R.A.; Oda, T.; Franca, B.B.; Mandarino, F.C.; Díaz Suárez, M.V.; et al. Global impact of COVID-19 restrictions on the surface concentrations of nitrogen dioxide and ozone. Atmos. Chem. Phys. 2021, 21, 3555-3592. doi: 10.5194/acp-21-3555-2021. [CrossRef]

19. Salma, I.; Vörösmarty, M.; Gyöngyösi, A.Z.; Thén, W.; Weidinger, T. What can we learn about urban air quality with regard to the first outbreak of the COVID-19 pandemic? A case study from central Europe. Atmos. Chem. Phys. 2020, 20, 15725-15742. doi: 10.5194/acp-20-15725-2020. [CrossRef]

20. Gualtieri, G.; Brilli, L.; Carotenuto, F.; Vagnoli, C.; Zaldei, A.; Gioli, B. Quantifying road traffic impact on air quality in urban areas: A Covid19-induced lockdown analysis in Italy. Environ. Pollut. 2020, 267, 115682. doi: 10.1016/j.envpol.2020.115682. [CrossRef]

21. Petetin, H.; Bowdalo, D.; Soret, A.; Guevara, M.; Jorba, O.; Serradell, K.; Pérez García-Pando, C. Meteorology-normalized impact of the COVID-19 lockdown upon $\mathrm{NO}_{2}$ pollution in Spain. Atmos. Chem. Phys. 2020, 20, 11119-11141. doi: 10.5194/acp-20-11119-2020. [CrossRef]

22. Higham, J.; Ramírez, C.A.; Green, M.; Morse, A. UK COVID-19 lockdown: 100 days of air pollution reduction? Air Qual. Atmos. Health 2021, 14, 325-332. [CrossRef]

23. Lee, J.D.; Drysdale, W.S.; Finch, D.P.; Wilde, S.E.; Palmer, P.I. UK surface $\mathrm{NO}_{2}$ levels dropped by $42 \%$ during the COVID-19 lockdown: impact on surface $\mathrm{O}_{3}$. Atmos. Chem. Phys. 2020, 20, 15743-15759. doi: 10.5194/acp-20-15743-2020. [CrossRef]

24. Grivas, G.; Athanasopoulou, E.; Kakouri, A.; Bailey, J.; Liakakou, E.; Stavroulas, I.; Kalkavouras, P.; Bougiatioti, A.; Kaskaoutis, D.G.; Ramonet, M.; et al. Integrating in situ Measurements and City Scale Modelling to Assess the COVID-19 Lockdown Effects on Emissions and Air Quality in Athens, Greece. Atmosphere 2020, 11, 1174. doi: 10.3390/atmos11111174. [CrossRef]

25. Collivignarelli, M.C.; Abbà, A.; Bertanza, G.; Pedrazzani, R.; Ricciardi, P.; Carnevale Miino, M. Lockdown for CoViD-2019 in Milan: What are the effects on air quality? Sci. Total Environ. 2020, 732, 139280. doi: 10.1016/j.scitotenv.2020.139280. [CrossRef] [PubMed]

26. Tobías, A.; Carnerero, C.; Reche, C.; Massagué, J.; Via, M.; Minguillón, M.C.; Alastuey, A.; Querol, X. Changes in air quality during the lockdown in Barcelona (Spain) one month into the SARS-CoV-2 epidemic. Sci. Total Environ. 2020, 726, 138540. doi: 10.1016/j.scitotenv.2020.138540. [CrossRef] [PubMed]

27. Sicard, P.; De Marco, A.; Agathokleous, E.; Feng, Z.; Xu, X.; Paoletti, E.; Rodriguez, J.J.D.; Calatayud, V. Amplified ozone pollution in cities during the COVID-19 lockdown. Sci. Total Environ. 2020, 735, 139542. doi: 10.1016/j.scitotenv.2020.139542. [CrossRef] [PubMed]

28. Huang, X.; Ding, A.; Gao, J.; Zheng, B.; Zhou, D.; Qi, X.; Tang, R.; Wang, J.; Ren, C.; Nie, W.; et al. Enhanced secondary pollution offset reduction of primary emissions during COVID-19 lockdown in China. Natl. Sci. Rev. 2020, 8, nwaa137.

29. Li, K.; Jacob, D.J.; Liao, H.; Qiu, Y.; Shen, L.; Zhai, S.; Bates, K.H.; Sulprizio, M.P.; Song, S.; Lu, X.; et al. Ozone pollution in the North China Plain spreading into the late-winter haze season. Proc. Natl. Acad. Sci. USA 2021, 118, e2015797118. doi: 10.1073/pnas.2015797118. [CrossRef]

30. Alexandri, G.; Georgoulias, A.K.; Balis, D. Effect of Aerosols, Tropospheric NO2 and Clouds on Surface Solar Radiation over the Eastern Mediterranean (Greece). Remote Sens. 2021, 13, 2587. doi: 10.3390/rs13132587. [CrossRef]

31. Hersbach, H.; Bell, B.; Berrisford, P.; Hirahara, S.; Horányi, A.; Muñoz-Sabater, J.; Nicolas, J.; Peubey, C.; Radu, R.; Schepers, D.; et al. The ERA5 global reanalysis. Q. J. R. Meteorol. Soc. 2020, 146, 1999-2049. doi: 10.1002/qj.3803. [CrossRef]

32. Chen, T.; Guestrin, C. XGBoost: A Scalable Tree Boosting System. In Proceedings of the 22nd ACM SIGKDD International Conference on Knowledge Discovery and Data Mining; Association for Computing Machinery, KDD '16, New York, NY, USA, 2016; pp. 785-794. doi: 10.1145/2939672.2939785. [CrossRef]

33. Granella, F.; Reis, L.A.; Bosetti, V.; Tavoni, M. COVID-19 lockdown only partially alleviates health impacts of air pollution in Northern Italy. Environ. Res. Lett. 2021, 16, 035012. doi: 10.1088/1748-9326/abd3d2. [CrossRef]

34. Bergstra, J.; Yamins, D.; Cox, D. Making a Science of Model Search: Hyperparameter Optimization in Hundreds of Dimensions for Vision Architectures. In Proceedings of the 30th International Conference on Machine Learning, Atlanta, GA, USA, 16-21 June 2013; Dasgupta, S., McAllester, D., Eds.; PMLR: Atlanta, GA, USA, 2013; Volume 28, pp. 115-123.

35. Koukouli, M.E.; Skoulidou, I.; Karavias, A.; Parcharidis, I.; Balis, D.; Manders, A.; Segers, A.; Eskes, H.; van Geffen, J. Sudden changes in nitrogen dioxide emissions over Greece due to lockdown after the outbreak of COVID-19. Atmos. Chem. Phys. 2021, 21, 1759-1774. doi: 10.5194/acp-21-1759-2021. [CrossRef]

36. Putaud, J.P.; Pozzoli, L.; Pisoni, E.; Martins Dos Santos, S.; Lagler, F.; Lanzani, G.; Dal Santo, U.; Colette, A. Impacts of the COVID-19 lockdown on air pollution at regional and urban background sites in northern Italy. Atmos. Chem. Phys. 2021, 21, 7597-7609. doi: 10.5194/acp-21-7597-2021. [CrossRef]

37. Deroubaix, A.; Brasseur, G.; Gaubert, B.; Labuhn, I.; Menut, L.; Siour, G.; Tuccella, P. Response of surface ozone concentration to emission reduction and meteorology during the COVID-19 lockdown in Europe. Meteorol. Appl. 2021, 28, e1990. doi: 10.1002/met.1990. [CrossRef]

38. Hersbach, H.; Bell, B.; Berrisford, P.; Biavati, G.; Horányi, A.; Muñoz Sabater, J.; Nicolas, J.; Peubey, C.; Radu, R.; Rozum, I.; et al. ERA5 Hourly Data on Single Levels from 1979 to Present. Copernicus Climate Change Service (C3S) Climate Data Store (CDS). 2018. Available online: https:/ / doi.org/10.24381/cds.adbb2d47 (accessed on 30 June 2021). 